\title{
Erratum to: A Comparison Principle for PDEs Arising in Approximate Hedging Problems: Application to Bermudan Options
}

Géraldine Bouveret ${ }^{1}$ • Jean-François Chassagneux ${ }^{2}$

\section{Erratum to: Appl Math Optim DOI 10.1007/00245-017-9413-5}

The original version of this article contained error in equations. Equations 3.7 and $3.10 \mathrm{c}$ are misplaced with different variants. This is corrected with this erratum.

The corrected equations are given below:

$$
\begin{gathered}
\left(\begin{array}{cc}
\mathcal{X} & 0 \\
0 & -\mathcal{R}
\end{array}\right) \leq \frac{3}{\varepsilon}\left(\begin{array}{cc}
I & -I \\
-I & I
\end{array}\right) \\
\left(\begin{array}{cc}
\mathcal{X}_{\varepsilon} & 0 \\
0 & -\mathcal{R}_{\varepsilon}
\end{array}\right) \leq \frac{3}{\varepsilon}\left(\begin{array}{cc}
I & -I \\
-I & I
\end{array}\right) .
\end{gathered}
$$

The online version of the original article can be found under doi:10.1007/s00245-017-9413-5.

Géraldine Bouveret

geraldine.bouveret@smithschool.ox.ac.uk

Jean-François Chassagneux

jean-francois.chassagneux@univ-paris-diderot.fr

1 University of Oxford, Oxford, UK

2 Laboratoire de Probabilités et Modéles Aléatoires CNRS, UMR 7599, Université Paris Diderot, Paris, France 